\title{
EXPRESSIVIDADE POÉTICA À FLOR DA TELA: ACORDES PARA $A$ TETA ASSUSTADA, WHISKY E O SEGREDO DE SEUS OLHOS ${ }^{1}$
}

\section{POETICAL EXPRESSIVENESS ON THE SKIN OF THE SCREEN: CHORDS TO A TETA ASSUSTADA, WHISKY AND O SEGREDO DE SEUS OLHOS}

\author{
Edvânea Maria da SILVA²
}

\begin{abstract}
Resumo: Os filmes A teta assustada (2009), de Claudia Llosa, Whisky (2003), de Juan Pablo Rebella e Pablo Stoll, e $O$ segredo de seus olhos (2009), de Juan José Campanella, como todo texto artístico, existem "somente no espírito que lhe[s] proporciona[m] sua realidade" (AUMONT, 1995, p. 225). As estratégias de cada cineasta dotaram as narrativas de poeticidade e abriram espaço para uma política da ficção. O objetivo deste artigo é investigar como o cinema latino-americano, representado em três filmes deste início de século, vem propondo novas formas de pensar o político e a subjetividade a partir de um fazer e olhar poéticos.
\end{abstract}

Palavras-chave: Poeticidade. Subjetividade política. Cinema latino-americano.

Abstract: The films A teta assustada (2009), directed by Claudia Llosa, Whisky (2003), directed by Juan Pablo Rebella and Pablo Stoll and $O$ segredo de seus olhos (2009), by Juan José Campanella, as any artistic text, exist "only in the spirit which endows them with reality" (AUMONT, 1995, p. 225). The strategies adopted by each filmmaker have impregnated the narratives with poetical quality and opened a space for a politics of fiction. The objective of this article is, therefore, to investigate how Latin-American cinema, represented in three early twenty-first century films, has proposed new ways of thinking about politics and subjectivity through a poetical action and vision.

Keywords: Poetical expressiveness. Political subjectivity. Latin-American cinema.

\section{O político e o poético no cinema latino-americano: uma breve introdução}

Cinematografia politizada. Talvez essa seja a característica mais presente quando se define certo cinema, feito na segunda metade do séc. XX, na América Latina, e que tem nos brasileiros Glauber Rocha (Terra em transe, 1967) e Nelson Pereira dos Santos (Vidas Secas, 1963), nos argentinos Fernando Pino Solanas (Los hijos de Fierro, 1975) e Fernando Birri (Tire dié, 1960) e no colombiano Victor Gaviria (La Vendedora de Rosas, 1998), só para citarmos alguns exemplos, vozes expressivas que se propunham a denunciar a violência de que foram (e são) vítimas os povos latino-americanos.

\footnotetext{
${ }^{1} \mathrm{O}$ presente artigo é um recorte da nossa pesquisa de doutorado intitulada "Expressividade poética à flor da tela: janelas para pensar três filmes latino-americanos" (UFPB, 2015), sob a orientação da Profa. Dra. Genilda Azerêdo.

${ }^{2}$ Doutora em Letras pela Universidade Federal da Paraíba (UFPB). Professora do Instituto Federal de Educação, Ciência e Tecnologia de Pernambuco (IFPE). E-mail: edvaneamaria@ yahoo.com.br.
} 
Acreditamos que os nascidos nesses anos épicos e violentos compreenderam o que representou o cinema político daquele período para Solanas e Birri, por exemplo. Hoje, principalmente no que diz respeito ao filme de ficção, há uma nova proposta de cinema político na América Latina. Nesse sentido, se pensarmos em produções mais recentes, nomes como os de Walter Salles (Terra Estrangeira, 1995; Linha de passe, 2008), Karim Aïnouz (Madame Satã, 2002; O Céu de Suely, 2006), Lucrecia Martel (O Pântano, 2001; A mulher sem cabeça, 2008), Pablo Trapero (Elefante branco, 2012; Abutres, 2010) respondem por uma diversidade de temas e estilos que, a seu modo, podem acender o debate e a discussão política.

Em "Por um cinema humanista: A identidade cinematográfica de Walter Salles, de $A$ grande arte até Abril despedaçado" (2007, p. 10), Mariana Mól Gonçalves observa que os filmes de Salles "evidenciam a migração e o exílio; a busca por uma segunda chance; e, principalmente, a transformação pelo afeto e a necessidade de se aprender a olhar o outro". A reiteração de temas como esses e a forma como jovens diretores latino-americanos narram suas histórias vão ao encontro dos trabalhos de Claudia Llosa, Juan Pablo Rebella e Pablo Stoll, e Juan José Campanella. São eles: A teta assustada, Whisky e O segredo de seus olhos.

Cada um, a seu modo, fala de uma nova subjetividade política, refletindo os sintomas de uma época a partir da vida ordinária de gente passível de ser encontrada nas calles (ruas). Esse, sem dúvida, é o ponto em comum dessas narrativas, cuja expressividade poética à flor da tela leva-nos a pensar as dores das gentes. Esses diretores não inovam na escolha da temática nessas narrativas; o que há de novo, melhor dizendo, de diferente, é como "uma realidade é sentida e descrita poeticamente" (D’ONOFRIO, 1983, p. 6, grifo nosso).

Para enunciar essa "realidade", os cineastas partem de sua visão subjetiva e, como "[o] Eu da lírica, torna[m]-se o[s] protagonista[s], refaz[em] o mundo através de suas percepções e devolve[m]-[n]o como uma forma de imaginação" (FREEDMAN, p. 271). Ainda de acordo com Freedman (p. 271), “[e]ste processo lírico se expande porque o "Eu” da lírica é também um protagonista em processo de experiência. Nesse sentido, A teta assustada, Whisky e $O$ segredo de seus olhos são, sim, narrativas poéticas. E a nova subjetividade política no cinema latino-americano é o acorde que "rege" a poeticidade dessas narrativas.

\section{Acordes para A teta assustada, Whisky e $O$ segredo de seus olhos}

Definido como "complexo sonoro de três ou mais frequências diferentes" (CUNHA, 1986, p. 11), o acorde serve-nos como exemplo de metáfora musical para pensar as consonâncias e dissonâncias entre as "notas", quer dizer, os filmes A teta assustada, de 
Claudia Llosa; Whisky, de Juan Pablo Rebella e Pablo Stoll; e O segredo de seus olhos, de Juan José Campanella.

$\mathrm{Na}$ teoria musical, a tríade de notas nomeia e determina o caráter do acorde que é formado pelas seguintes notas: fundamental (dá origem ao acorde), $3^{\text {a }}$ (modal: maior/menor) e $5^{\text {a }}$ (justa). Numa leitura incipiente e insipiente, e dentre as diversas possibilidades, teríamos a

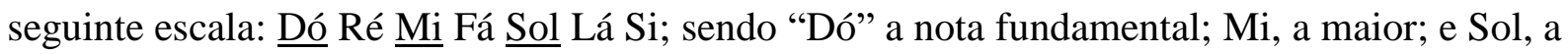
justa, a que fica entre uma nota aumentada e uma diminuta. A essa combinação, chamamos "Dó Maior".

A analogia se dá, num primeiro momento, porque o termo acorde nos remete, também, a acordo, à harmonia, algo não exclusivo do universo da música; num segundo momento, porque o nosso acorde é formado por três filmes de frequências, leia-se países, diretores, estilos/propostas, diferentes. Entretanto, para o nosso propósito, interessa-nos pensar A teta assustada, Whisky e $O$ segredo de seus olhos como "notas" que, sem aquela classificação valorativa (fundamental, modal, justa/aumentada/diminuta), soam juntas e produzem um novo acorde; dizendo de outro modo, produzem uma nova subjetividade política no cinema latinoamericano deste início de século. Vejamos.

A teta assustada é a história de uma indígena, que é violentada à época do conflito armado no Peru, tendo sido inspirada em eventos e registros históricos de mulheres indígenas vítimas das muitas atrocidades cometidas tanto pelo Exército peruano quanto pelos integrantes do movimento terrorista peruano Sendero Luminoso. O filme de Llosa é adaptado do testemunho de Salomé Baldeón (THEIDON, 2004), moradora do Distrito de Accomarca (Peru) e uma das muitas vítimas de violência sexual das comunidades campesinas ayacuchanas, da segunda metade da década de oitenta do séc. XX.

Whisky é o registro da vida de Jacobo e Marta. Aquele é dono de uma velha fábrica de meias na capital uruguaia; Marta é seu braço direito há muitos anos, mas a relação deles é estritamente profissional. A rotina de Jacobo é ameaçada com a chegada de Hérman, que veio ao país para a cerimônia do Matzeivá - conforme reza a tradição judaica, cerimônia da pedra tumular colocada um ano (ou um mês) após a morte da mãe deles. Marta e Jacobo são personagens solitários, e a chegada de Hérman é a mola propulsora para despertar a antiga rivalidade entre os irmãos e para que os silêncios do filme comecem a falar.

No que se refere a $O$ segredo de seus olhos, a Argentina dos anos 70 serve como pano de fundo para Benjamín Espósito, personagem-escritor e oficial de justiça de um tribunal penal recém aposentado, narrar uma história trágica. Mas a narrativa vai além desse terreno: 
flerta com o film noir; assume-se como melodrama com todos os "ingredientes", a saber, a estrutura, o tema, o drama histórico e a presença do bobo (representado na figura de Pablo Sandoval, amigo de Espósito); além, e certamente aí reside seu maior mérito, a utilização do recurso da metaficção.

Tal mérito se justifica porque a narrativa autoconsciente de Campanella é construída a partir de dois processos que são mantidos juntos em uma tensão formal, que quebra as distinções entre criação e crítica, fundindo-os nos conceitos de interpretação e desconstrução (WAUGH, 1984, p. 6). De acordo com Stam (1981, p. 19), “a arte tem sido alimentada por essa tensão constante entre ilusionismo e reflexividade." O filme/romance alterna momentos de ilusionismo e reflexividade, em que o personagem-escritor ora age como um "batoteiro" (STAM, p. 19) - contando-nos a sua história, ou melhor, a de Ricardo Morales, deliciandonos com a narração dos fatos, fazendo-nos acreditar que (quase) tudo se passou como vemos/lemos na tela -, ora como um "desmancha-prazeres".

Ao ser um desmancha-prazeres, Benjamin Espósito não só revela o seu fazer literário, ou seja, o processo de construção de $O$ segredo de seus olhos, como também aponta para uma reflexão sobre o estar no mundo. Diante de uma realidade que se anunciava sensaborosa, a saber, a de aposentado - numa sociedade que valoriza a juventude e a produção, ignorando a contribuição dada pelo trabalhador ao longo de uma vida - a linha de fuga de Espósito é a escrita do romance. É nela que o personagem-escritor vive uma "experiência interiorizante" (AZERÊDO, 2012, p. 267), realiza uma ação política, "uma atividade política de resistência" (ALMEIDA, 2008, p. 2), pois coloca em xeque convicções, hábitos e o sentido da vida.

É importante destacar que outras produções realizadas nesse período, com temáticas diversas podem, se assim o pesquisador/crítico/leitor/espectador do texto/filme entender, formar "acordes" diversos daquele. E, como ocorre na esfera musical, esses acordes também poderão ser formados a partir de consonâncias e dissonâncias.

No caso de A teta assustada, Whisky e $O$ segredo de seus olhos, a consonância diz respeito ao fato de esses filmes falarem do cotidiano das pessoas comuns, o que se revela como uma partilha do sensível (RANCIÈRE, 2009); e, ao dar visibilidade aos personagens de suas narrativas, ou seja, à gente comum, os cineastas abrem espaço para a política da ficção (RANCIÈRE, 2007).

Essas narrativas são construídas a partir de estratégias criativas, que promovem tensões, ambiguidade e polissemia, e, a exemplo do que fez o Cinema Novo, abrem espaço para contar a história dos anônimos e de sua rotina. Entretanto, enquanto o cinemanovista buscava mover 
“o "povo" à ação, tanto pelo conteúdo como pela linguagem incômoda dos filmes, muitas vezes em narrativa descontínua" (SANTOS, 2012, p. 8, grifo do autor), o cinema latinoamericano (brasileiro e de língua hispânica), deste início de século, busca/apresenta uma tonalidade diferente daquela dos anos 60. E, mesmo quando parece enveredar por uma via do debate político, o faz sob outro prisma, outra abordagem. Não há uma ruptura, um corte, mas uma adequação aos novos tempos.

Retomando a discussão acerca dos acordes, entendemos que os dissonantes, no sentido mais corriqueiro do termo, a princípio, podem ser percebidos na recepção crítica dos filmes $A$ teta assustada e $O$ segredo de seus olhos, em seus países de origem. Neste, Campanella é chamado de autor industrial que dialoga com a matriz hollywoodiana e o melodrama argentino; a "classificação" soa pejorativa. Naquele, Llosa é acusada de ser racista e "estrangeira"; parece-nos que parte desse público esperava um filme à moda de Francisco Lombardi. Em ambos os casos, Campanella e Llosa estão em desacordo, são dissonantes.

Interessa-nos, entretanto, outra dissidência, a da configuração da experiência dos narradores/cineastas que abandonam o cinema político engajado e adentram no universo das dificuldades do ser humano, da sua solidão, do seu silêncio, dos seus medos, novas formas de subjetividade política.

Como na música, essa dissonância no interior do acorde é harmonizada e resulta "em algo belo - tenso, mas belo" (BARROS, 2013, p. 28). Em “Acordes Teóricos - a música como um modelo possível para repensar a teoria na História e em outros campos de saber", José D‘Assunção Barros observa também que

\footnotetext{
$\mathrm{O}$ acorde, reunindo em um feixe único as suas notas estruturais e as suas dissonâncias, constitui em si mesmo uma 'unidade artística'. Mas o segundo milagre é que o 'acorde tenso' também desempenha uma função importante, imprescindível, na verdade, no conjunto dos demais acordes. Sem os acordes tensos, a harmonia não existiria. Poderíamos, metaforicamente, dispensar alguns acordes consonantes; mas os acordes dissonantes são imprescindíveis (BARROS, p. 28).
}

O primeiro "milagre" é o da harmonização das dissonâncias, algo que se torna possível graças ao arranjo dos "arranhões", ou seja, das notas dissonantes, imprescindíveis, sim, pois, sem eles/elas (arranhões/notas), não haveria poeticidade nos filmes em questão. Nesse sentido, como "dispensar" a fecundação da batata em A teta assustada, os tempos mortos em Whisky, a escrita do romance de Benjamín Espósito em $O$ segredo de seus olhos?

Diríamos que o estranhamento "mor", no filme de Claudia Llosa, surge com a batata, e o leitor/espectador desavisado pode deixar passar os sentidos que esse tubérculo encerra. A 
inserção da batata na vagina da protagonista causa estranhamento - tanto no sentido corriqueiro do termo como naquele proposto pelos formalistas russos - na narrativa; problematiza a questão da violência simbólica de que é vítima o indígena (peruano); e, não menos importante, recria um mito na narrativa oral.

Sensível às questões de sua gente, mas consciente de que realiza uma ficção, Llosa molda elementos históricos a eventos imaginários e adiciona pequenos sons/eventos que, juntos, responderão por um acorde mais complexo, carregado de poeticidade.

Através da imagem visual (e sonora) do "acorde" - capaz de materializar várias coisas que acontecem ao mesmo tempo, e mesmo aquelas influências invisíveis ou menos audíveis, que são os 'harmônicos' - podemos compor para um autor um quadro de influências e traços característicos ('notas') tão complexo quanto desejemos (BARROS, p. 23).

A citação é uma referência à historiografia, mais especificamente à imagem do 'acorde teórico' como recurso para capturar algo da "complexidade teórica" de historiadores, conforme defende José D“Assunção Barros; isso, entretanto, não nos impede de, a partir da metáfora musical, identificar "harmônicos" em A teta assustada. Longe de pretender ver nisso uma influência/característica na/da filmografia de Claudia Llosa, esses harmônicos, aqui entendidos como detalhes aparentemente insignificantes, ajudam a compor uma nota, ou melhor, um filme mais complexo.

Como exemplo de influência "menos audível", citamos a preferência da protagonista por determinada planta.

\footnotetext{
En el jardín hay Geranios, Camelia, Margarita, Cactus, Camote, todo, me-nos papa.

Y tú porqué tienes miedo a andar sola por la calle.

Porque sí.

Del mismo modo, porqué quiero.

Yo no tengo miedo porque quiero.

Sólo la muerte es obligatoria. Lo demás, es porque queremos.

¿Y cuando te matan y cuando te violan qué? ¿Eso no es obligatorio! - dito isso, Fausta encaminha-se para a saída, e Noé responde à sua pergunta inicial.

La papa es barata y florece poco ${ }^{3}$.
}

O diálogo acima (quase uma discussão), entre Fausta e o jardineiro, alterna o banal por que não cultivar determinada planta - com o complexo: o medo da protagonista de, como sua mãe, ser vítima da violência sexual; retomando a questão nada simples, o valor da batata.

\footnotetext{
${ }^{3}$ No jardim há gerânios, camélia, margarida, cacto, camote, tudo, menos batata./ E tu, por que tens medo de andar sozinha pela rua?/ Porque tenho./ Do mesmo modo, porque quero [plantar gerânios, camélia, etc]./ Eu não tenho medo porque quero. / Só a morte é obrigatória. O restante é porque queremos./ E quando te matam e te violentam? Isso não é obrigatório!/ A batata é barata e floresce pouco.
} 
O valor desse tubérculo ultrapassa as questões econômicas; na verdade, tensiona o vocábulo "batata" (como a chamamos) que é símbolo da identidade cultural do povo andino ${ }^{4}$. Dizendo de outro modo, las papas tienen valor.

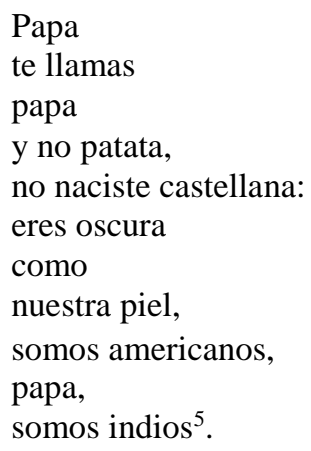

O poema Oda a la papa, de Pablo Neruda (LA GACETA, 2011), confirma o valor do tubérculo e ratifica a relevância da indagação/cobrança de Fausta, pois está diretamente ligada à questão da identidade do povo andino - embora la sirena "venda" suas raízes. Sua preferência por la papa é compreensível e soa harmônica. Há, ainda, dois eventos/duas cenas, aparentemente menos audíveis (os lugares destinados a esconder o corpo de Perpétua, mãe de Fausta, enquanto a protagonista busca condições financeiras para sepultá-lo), que merecem nossa atenção por reforçar o tema morte e vida que perpassa toda a narrativa.

É o noivado de Máxima, prima da protagonista, e a casa está em festa. Enquanto (quase) todos felizes celebravam o evento, a protagonista foi até a sua casa e não encontrou o corpo de sua mãe. Aflita, voltou à festa perguntando onde estava Perpétua. O tio indicou-lhe que o filho saberia onde ela se encontrava. O rapaz deu-lhe o "itinerário" e Fausta encontrou-a embaixo da cama, sob o vestido de noiva. O corpo sem vida de Perpétua estava encoberto por um símbolo de vida.

Ao longo do filme, vemos o tio cobrar a Fausta a promessa [do sepultamento] e dizer que sua filha Máxima iria se casar e que não desejaria um cadáver em sua casa. Acompanhamos "de perto" a peregrinação de Fausta, vendo-a ir de uma funerária a outra sem grande sucesso devido aos preços, sem contar o valor cobrado para o traslado do corpo; ouvimos/vemos, também, propostas inusitadas para a "resolução" do seu problema: como

\footnotetext{
${ }^{4}$ Los italianos la llaman patata, los ingleses potato, los suecos potati, los franceses la relacionaron con la manzana y la llaman pomme de terre, en Alemania se llama kartoffel, que es una variante de la palabra trufa. En Rusia y en Polonia la referencia a trufas permanece en el término kartofel. Nosotros las llamamos papas, como debe ser, que es el nombre quechua y que aparece por primera vez en un texto castellano de 1540.

$5 \mathrm{Papa} / \mathrm{te}$ chamas/papa/e não batata/não nasceste castelhana:/és escura/como/nossa pele,/somos americanos,/papa,/somos índios.
} 
levar, no ônibus, o caixão junto com as malas, ou, ainda, alugar um ataúde por uma noite e, no dia seguinte, desenterrar o corpo e procurar um lugar mais barato (!).

Independente da promessa de Fausta, o seu tio segue cavando um buraco, e o formato que este estava tomando em muito se assemelhava a um túmulo, a ponto de um dia, ao retornar do trabalho, Fausta ir em sua direção, acreditando que o tio havia enterrado Perpétua no quintal de casa. Como Fausta, surpreendemo-nos ao constatar que o lugar outrora destinado à morte estava lleno de vida.

Parece-nos que, ao cavar, o tio de Fausta encontrou água, transformando o "buraco" num espaço de lazer não só das crianças, mas de toda a família, como na imagem em que o tio faz "marinheiro" antes de mergulhar na piscina, enquanto em volta percebemos cadeiras de praia, homens e mulheres não só tomando sol, mas também passando bronzeador ou protetor solar. Vemos tudo isso à distância da janela da casa, filtrado pelo olhar de Fausta.

Sem dúvida, a montagem reforça o tema morte e vida. Eisenstein $(2002$, p. 28) afirma que "a montagem tem um significado realista quando os fragmentos isolados produzem, em justaposição, o quadro geral, a síntese do tema. Isto é, a imagem que incorpora o tema”. Para Lotman (1978, p. 118), "O tema é a sequência dos elementos significantes de um texto, dinamicamente oposto ao seu sistema de classificação". Para nós, os elementos/imagens são significantes em A teta assustada devido a uma organização harmônica/poética do tema.

Ainda sobre "vida que nasce morta", observamos que a montagem não só produz a síntese do tema, mas inclui "no processo criativo a razão e o sentimento do espectador" (EISENSTEIN, p. 29). Como acontece na composição do acorde musical, no cinema, as notas/cenas tocadas/mostradas isoladamente não significam. É preciso pensá-las/selecionálas/harmonizá-las de tal modo que possamos descobrir

\begin{abstract}
Como através desta ordenação podem ser criadas reações mentais no espectador, que apelam ao subjetivo, poético, onírico. Ele [o processo de montagem] deu ao filme seu instrumento mais valioso para ir de um entretenimento ou "curiosidade de barraca de feira" a uma arte totalmente consolidada (LÓPEZ JUAN, 2003, p. 104, grifo nosso, tradução nossa) $)^{6}$.
\end{abstract}

$\mathrm{Na}$ analogia com as notas de uma escala, as cenas (os planos) podem, como acontece no universo da música, ser "fetichizadas como talismãs dotados de certos poderes psicossomáticos” (WISNIK, 1989, p. 75). Dizendo de outro modo, podem ser uma

\footnotetext{
${ }^{6}$ Lo interesante de este proceso [montaje] es descubrir cómo a través de esta ordenación se pueden crear reacciones mentales en el espectador, que apelan a lo subjetivo, poético y onírico. Se dotó al cine de su herramienta más valiosa para pasar de ser un entretenimiento o curiosidad de barraca de feria a un arte plenamente consolidado (LÓPEZ JUAN, 2003, p. 104).
} 
“manifestação de uma eficácia simbólica (dada pela possibilidade de detonarem diferentes disposições afetivas: sensuais, bélicas, contemplativas, eufóricas, outras)" (WISNIK, p. 75).

Em Whisky, as notas/os planos "detonam” e conotam disposições de ausência de afeto (ou, pelo menos, dificuldade em expressá-lo), de silêncio, de solidão. Isso é possível a partir da seleção e combinação de imagens/notas no filme que criam, possibilitam leituras significativas. No filme de Rebella e Stoll, há tempos mortos, imagens repletas de repetições do cotidiano: da vida como ela é. Entretanto, esses tempos "não mostram somente as banalidades da vida cotidiana"; eles vão além: "coletam as consequências ou o efeito de um acontecimento relevante" (DELEUZE, 2005, p. 16).

Algumas dessas banalidades/imagens reforçam o efeito da solidão e do silêncio de Whisky, e o pouco que é dito está longe do dizer da câmera que nos narra as consequências da partida de Hérman na vida afetiva e profissional de Jacobo. A título de exemplo, citamos a visita que Marta faz ao apartamento de Jacobo, a fim de conhecer o lugar onde viveria como a mais nova senhora Köller. O espaço é um lugar de não-acontecimentos, de uma vida cheia de nada, e a câmera/o olho de Marta vai ratificando o que sabíamos de Jacobo desde o início do filme.

O ambiente desarrumado revela o quarto de um homem solitário, cujos interesses resumiam-se a olhar catálogos de revistas sobre máquinas industriais e a torcer por seu time do coração, El Tanque Sisley. No quarto, são visíveis as revistas sobre aquele tema, bem como troféus e medalhas que revelam o interesse dele por futebol; certamente, um dos seus poucos prazeres.

O quarto em que o "casal" dormiria, a exemplo da sala de estar/jantar, dá-nos a impressão de que, em algum momento, seria desocupado. Teria Jacobo começado a guardar os objetos que foram de sua mãe? Vemos camas que há muito não são usadas; objetos de uso pessoal como a aparadeira, a almofada terapêutica, o cilindro de oxigênio, colchões em sacos plásticos, além de um espelho recém tirado da parede da penteadeira, e Marta que olha para tudo aquilo.

De um modo geral, há em Whisky uma economia de palavras e nesse tour que Jacobo e Marta fazem pelo apartamento não é diferente. Entretanto, é a partir desses tempos mortos, desses objetos fora de lugar, que sabemos um pouco mais do drama de Jacobo e da vida que ele poderia ter tido. Isso nos faz pensar - como acontece na leitura que Ursula Rösele faz de Casa vazia (2004), filme de Kim Ki-duk - que, em Whisky, a câmera medeia um 
'Colóquio' silencioso com o Cinema que não se dá em um esforço metalinguístico explícito, mas fazendo contornos em torno de sua estrutura onde podemos perceber que o maior diálogo do filme se dá através do não-dito e de tudo aquilo possível de ser transposto através do olhar [...].

O não-dito em Whisky materializa-se, também, a partir de influências, aparentemente, menos audíveis, como no par de alianças que Jacobo retira de seu bolso depois do tour que ambos fizeram:

Bem, e isso seria para...

Sim, claro, completa Marta.

Marta coloca a aliança em seu dedo; olha para mão de um modo como uma noiva faria, admirando o seu novo estado civil; em seguida, coloca-a rente ao corpo, fazendo com que o símbolo daquela encenação caísse no piso e rolasse para debaixo da mesa. Marta encontra a aliança e pergunta a Jacobo se era de sua mãe. Observa que ficou grande, diz-lhe que tem um vizinho joalheiro e que poderia levá-la para consertar. Jacobo dá de ombros e concorda. Em seguida, como havia feito em todas as sequências em que mostrou cada um dos cômodos a Marta, apaga a luz como se encerrasse/concluísse não só o assunto, mas, principalmente, os ajustes da encenação, independente da escassez das palavras.

A indiferença de Jacobo e a preocupação de Marta em relação ao (não) ajuste da aliança remetem-nos às certezas daquele e aos sonhos, às esperanças desta. Jacobo havia dito a Marta que só era preciso que ela ficasse na casa dele enquanto Hérman estivesse hospedado lá; nesse sentido, "dar de ombros" é como se não visse motivo para tal preocupação. Afinal, quando Hérman partisse, tudo voltaria a ser como era antes. Por outro lado, a sugestão de Marta para ajustar a aliança revela não só o sonho do matrimônio - desejo da maioria das mulheres -, mas também o desconforto com o "tamanho da aliança": elemento sugestivo do final desalentador.

Esse arranhão, essa "nota" dissonante desse elemento na mise-en-scène torna complexo o acorde/a farsa do casamento, pois a aliança está longe de ser uma "reunião", uma “associação" (CUNHA, 1986, p. 31). O esmero com que Marta cuida da sala de estar/jantar e do quarto de casal soa-nos como uma tentativa de mostrar a Jacobo a possibilidade de uma aliança, de uma nova vida, de uma vida a dois, de algo que, talvez, não estivesse nos planos dele. Em outras palavras, tornar real a farsa.

Nesse sentido, Marta é pseudo-cúmplice da encenação. Jacobo, entretanto, parece lembrar-lhe que tudo não passa de um acordo. Sendo assim, já na primeira noite em que 
Hérman chegou e sem que este percebesse, Jacobo desfez a cama de casal. No final da narrativa fílmica, mais uma vez, Jacobo reforça a ideia de encenação quando paga a Marta por tê-lo ajudado a manter as aparências. Marta afirma que não é necessário, mas Jacobo lhe diz que é uma forma de retribuição.

Com a partida de Hérman, o "casamento" se desfaz e a encenação já não é mais necessária. Jacobo se encarrega de desfazer o cenário que Marta havia montado. Ou seja, a cama de casal é desforrada e separada, dando lugar a duas camas de solteiro; a cadeira de rodas é (re)conduzida, provavelmente, à sala de estar/jantar, remetendo-nos às primeiras imagens que vimos, por ocasião da primeira visita de Marta ao apartamento.

Um outro dado, não menos relevante, é o da baixa luminosidade que irá ratificar o valor semiológico dos tempos mortos. Finda a farsa, Jacobo está de volta à penumbra; ao isolamento; ao reencontro com a sua história; para usarmos uma expressão corriqueira, “sente-se em casa”. Para Bachelard (1993, p. 26),

Se nos perguntassem qual o benefício mais precioso, diríamos: a casa abriga o devaneio, a casa protege o sonhador, a casa permite sonhar em paz. [...] Na vida do homem, a casa afasta contingências, multiplica seus conselhos de continuidade. Sem ela, o homem seria um ser disperso. Ela mantém o homem através das tempestades do céu e das tempestades da vida.

Diferente da casa descrita por Bachelard, a casa de Jacobo não "abriga o devaneio", não "protege o sonhador", mas talvez permita esconder-se em paz. A casa de Jacobo, tal qual a conhecemos no início e final do filme, "afasta contingências"; em outras palavras, mantém Jacobo longe de uma possível e real, pelo menos na diegese, aliança com Marta. Além de desfazer qualquer possibilidade de união entre eles: tudo permaneceria como sempre estivera.

Diferente ainda do homem são "que deveria suportar, sem fraqueza, deslocamentos ou mudanças", Jacobo é um homem frágil e, para não perder "as paredes tranquilizadoras, esse homem se agarra aos objetos para não perder sua história” (PANKOW, 1988, p. 85). Jacobo não suporta a mudança; por isso, desfaz a mise-en-scène, devolve os objetos ao seu lugar de “origem" e recebe de Marta a aliança; afinal, a encenação havia terminado. As esperanças, os sonhos dela também. Se em Whisky o silêncio vibra como uma corda, e os tempos mortos ressoam o não-dito, em $O$ segredo de seus olhos, os tempos mortos ressoam modos de dizer algo.

Construído a partir de uma linguagem metaficcional, o filme de Campanella lembra-nos um acorde formado por consonância e dissonância. Por dissonância, entendemos o processo 
de crítica, de reflexividade; por consonância, o processo de criação artística, de ilusionismo. A tensão entre esses "acordes" é imprescindível para a composição de qualquer texto metaficcional; neste caso, para a escrita do romance de Benjamín Espósito.

Harmonizado o acorde, há de se olhar para os harmônicos, ou seja, para os vários gêneros textuais, a exemplo do chiste, do memorando, da carta, da fotografia - no caso de $O$ segredo de seus olhos, eles nos soam bem audíveis -, que conferem ao filme um grau maior de complexidade. Como ocorre na música, esses gêneros textuais correspondem "a uma simultaneidade de sons, a um feixe transversal de notas musicais que passam a interagir uma com a outra de modo a formar uma coisa nova" (BARROS, p. 21).

Há, também, como ocorre na composição musical, imagens/cenas que soam menos audíveis, quase como se não acrescentassem algo mais ao acorde/filme; entretanto, essas imagens ratificam o caráter metalinguístico da narrativa e prestam uma homenagem ao cinema. No filme de Campanella, destacamos um desses momentos, uma imagem-clichê que é, claramente, uma referência à literatura policial americana da primeira metade do século $\mathrm{XX}$, bem como à série de TV e a filmes para o cinema da segunda metade do mesmo século. Vejamos o diálogo abaixo:

Estou quase urinando, diz Sandoval.

Espere mais um pouco. A senhora (mãe de Isidoro Gómez) já deve estar saindo. Assistiu a filmes demais com Napoleon Solo e Perry Mason. Esse é o seu problema. - observa Sandoval. Em seguida, completa: Eu realmente tenho que fazer xixi.

Antes da referência a Napoleon Solo e a Perry Mason, o detetive Baéz - investigador oficial do assassinato de Liliana Colotto - havia se identificado como Mike Hammer, "arquétipo do detetive linha-dura", personagem criado por Mickey Spillane ${ }^{7}$, em resposta irônica ao mestre de obras quando investigava o paradeiro de Isidoro Gómez, numa construção em que este trabalhara. A resposta, sem dúvida, é uma tentativa de intimidação e tem o efeito esperado, pois Báez e Benjamín conseguem o último endereço do assassino de Liliana.

Se Báez é “Mike Hammer”, Benjamín - segundo o comentário de Sandoval - seria uma mistura de Napoleon Solo $^{8}$ e Perry Mason $^{9}$ que teriam a paciência como característica

\footnotetext{
${ }^{7}$ Após criar várias histórias em quadrinhos, incluindo algumas para a editora que viria a dar origem à Marvel atual, Spinalle escreveu seu primeiro romance tendo Mike Hammer como personagem principal, Eu, oJúri, em 1946\|. Disponível em: <http://cultura.estadao.com.br/noticias/geral,morre-mickey-spillane-criador-do-detetivemike-hammer,20060717p3366>. Acesso em: 13 dez. 2014.

${ }^{8}$ Personagem criado por Ian Fleming, Solo foi uma versão de James Bond para a telinha na série de espiona-gem americana The Man from UNCLE (United Network Command for Law and Enforcement), exibida na televisão
} 
comum, conforme observação de Sandoval. Mason era um personagem de uma série televisiva homônima de 1957 a 1966 (mas também personagem de rádio e de filmes para cinema, entre os anos 30 e 50), que defendia seus clientes de acusações de assassinato; Solo, um agente da série televisiva The Man from UNCLE, que trabalhava em conjunto com outro espião no auge da Guerra Fria.

A cena descrita acima lembra-nos uma imagem-clichê de investigadores fazendo vigília, e a paródia que $O$ segredo de seus olhos faz às histórias de detetives não fica na superfície da narrativa de Benjamín/Campanella, com a referência aos personagens acima citados. Nesse sentido, chamamos a atenção para certo paralelismo entre as narrativas de que fazem parte os personagens Mike Hammer, Espósito e Sandoval.

Hammer é o personagem principal de um clássico noir: A Morte num Beijo (Kiss me deadly, 1955, adaptação do romance homônimo de Spillane), filme de Robert Aldrich, cuja narrativa "é um audacioso comentário pessimista sobre a paranóia da Guerra Fria e o medo de um Holocausto atômico, fantasmas que assombravam a população norte-americana do período. [...]" que investe em "um visual repleto de sombras e espaços escuros, para comentar a situação política da época", conforme afirma Rodrigo Carreiro ${ }^{10}$.

Benjamín Espósito e Pablo Sandoval, por sua vez, são personagens de uma narrativa que vai além da história policial, sem beijo algum, que faz uma revisão histórico-política9 rememorando a "burocracia estatal e a negligência dos agentes do sistema judiciário" em tempos de pré-golpe de estado na Argentina dos anos $70^{11}$. Parafraseando José D“Assunção Barros (2013, p. 23), tudo isso acontece "através de uma imagem visual (e sonora) do 'acorde"" em $O$ segredo de seus olhos que nos ajuda a compor o quadro de influências de Campanella.

Sobre o fato de o filme não ficar na superfície e ir além da narrativa policial, Eduardo Sacheri afirma a Daniel Sendrós (2009) que O segredo de seus olhos é “em última e terrível instância, como no romance [La pregunta de sus ojos]", "uma reflexão sobre o castigo". Dentre as possíveis reflexões que o romance de Eduardo Sacheri suscita, destacamos o fato de

de 1964 a 1968. Disponível em: <http://pt.wikipedia.org/wiki/The_Man_from_U.N.C.L.E>. Acesso em: 22 jan 2013.

${ }_{9}^{9}$ Personagem criado por Erle Stanley Gardner, cujos livros sobre o personagem venderam mais de 130 milhões de exemplares só nos Estados Unidos, até 1970, ano da morte de Gardner. Disponível em: <http://pt.wikipedia.org/wiki/Perry_Mason>. Acesso em: 25 jan. 2013.

${ }^{10}$ Disponível em: http://www.cinereporter.com.br/criticas/morte-num-beijo-a/. Acesso em: 22 jan. 2013.

${ }^{11}$ Disponível em: http://www.revistacriterio.com.ar/cultura/el-secreto-de-sus-ojos-los-de-juan-jose-campanella/. Acesso em: 19 jan. 2013. 
ele ser "menos uma diversão do que um escudo contra as ameaças externas e internas, obrigando-nos a narrar uma luta interminável: o drama que nos constitui” (BERNARDO, 2010, p. 20).

Ser humano. Esse drama ressoa também em A teta assustada e Whisky a partir, como já observado, de diálogos/imagens/cenas (pouco) audíveis que se destacam aos nossos olhos e ouvidos (BARROS, p. 25) e que, graças aos arranjos dados por Claudia Llosa, Juan Pablo Rebella e Pablo Stoll, e Campanella ajudam a produzir um novo acorde, uma nova subjetividade política no cinema latino-americano.

$* * *$

José D“Assunção Barros (2013, p. 25) afirma que “quem produz o acorde é, no fundo, o leitor. $\mathrm{O}$ autor compõe um ambiente harmônico a partir do qual surgem certas possibilidades de leitura". No duplo papel que desempenhamos ao longo dessas linhas, propusemos possibilidades de leituras para os filmes-objeto deste artigo; foram leituras diversas, mas nem por isso menos harmônicas. Foram olhares, miradas, sobre a expressividade poética à flor da tela em A teta assustada, Whisky e $O$ segredo de seus olhos.

\section{Referências}

A TETA assustada. Direção e Roteiro: Claudia Llosa. Intérpretes: Magaly Solier, Susi Sanchéz, Efraín Solís. Produção: Claudia Llosa. Peru-Espanha, 2009. 1 DVD (93 min), son., col.

ALMEIDA, Leonardo Pinto de. Literatura e Subjetividade: reflexões sobre a linguagem e o exercício da liberdade. In: IV Encontro de Estudos Multidisciplinares em Cultura, 2008, Salvador-Ba. Salvador-Ba: Cult/Pós-Cultura (UFBA), 2008. Disponível em: <http://www.cult.ufba.br/enecult2008/14418.pdf>. Acesso em: 31 mar. 2014.

AUMONT, Jacques et al. A estética do filme. Tradução de Marina Appenzeller. Campinas: Papirus, 1995.

AZERÊDO, Genilda. Linha de passe e o diálogo lírico com a estética de documentário. In: BRANDÃO, Alessandra; JULIANO, Dilma; LIRA, Ramayana. Políticas dos cinemas latinoamericanos contemporâneos: múltiplos olhares sobre a cinematografia latino-americana atual. Palhoça: Ed. Unisul, 2012, p. 265-280.

BACHELARD, Gaston. A poética do espaço. Tradução: Antônio de Pádua Danesi. São Paulo: Martins Fontes, 1993. 
BARROS, José D“Assunção. Acordes Teóricos - a música como um modelo possível para repensar a teoria na História e em outros campos de saber. Lusíada. História n. ${ }^{\circ}$ 9, out/2013, p.11-38. Lisboa: Universidade Lusíada.

BERNARDO, Gustavo. O livro da metaficção. Rio de Janeiro: Tinta Negra Bazar Editorial, 2010.

CUNHA, Antônio Geraldo da. Dicionário etimológico Nova Fronteira da língua portuguesa. 2 ed., Rio de Janeiro: Nova Fronteira, 1986.

DELEUZE, Gilles. A imagem-tempo. Tradução: Eloisa de Araújo Ribeiro; revisão filosófica Renato Janine Ribeiro. São Paulo: Brasiliense, 2005.

D‘ONOFRIO, Salvatore. O texto literário: teoria e aplicação. São Paulo/Rio de Janeiro: Duas Cidades, 1983.

EISENSTEIN, Sergei. O sentido do filme. Tradução: Tereza Ottoni. Rio de Janeiro: Jorge Zahar Ed., 2002.

FREEDMAN, Ralph. The lyrical novel: studies in Hermann Hesse, André Gide and Virginia Woolf. New Jersey: Princeton University Press, 1963.

JUARROZ, Roberto. La última conversación con Roberto Juarroz. Entrevistadora: Martha Vargas. Revista Generación Abierta, Buenos Aires, 1994. Disponível em:

<http://www.generacionabierta.com.ar/notas/20/juarroz.html>. Acesso em: 05 mai. 2014.

LA GACETA. Oda a la papa. Poema de Pablo Neruda. Sociedad, Jueves 07 de Julio 2011. Disponível em: <http://www.lagaceta.com.ar/nota/444337/tucumanos/oda-papa.html>. Acesso em: 22 jun. 2018.

LÓPEZ JUAN, Aramis Enrique. El lenguaje cinematográfico. In: Estudio de las fuentes cinematográficas para la investigación y docencia de los procesos urbanos: los barrios marginales de las ciudades españolas. Tesis Doctorales. Unversidad: Alicante, 2003.

LOTMAN, Yuri. Estética e semiótica do cinema. Tradução: Alberto Carneiro. Lisboa: Editorial Estampa, 1978.

NÚÑEZ, Fabián Rodrigo Magioli. O que é nuevo cine latino americano? O Cinema Moderno na América Latina segundo as revistas especializadas latino-americanas. Tese (Doutorado) Programa de Pós-Graduação em Comunicação, Universidade Federal Fluminense, Niterói, 2009.

O SEGREDO de seus olhos. Direção: Juan José Campanella. Intérpretes: Ricardo Darín, Soledad Villamil, Pablo Rago. Roteiro: Eduardo Sacheri e Juan José Campanella. Produção: Gerardo Herrero, Mariela Besuevsky e Juan José Campanella. Argentina-Espanha, 2009. 1 DVD (125 min.), son., col., baseado no romance La pregunta de sus ojos, de Eduardo Sacheri.

PANKOW, Gisela. O homem e seu espaço vivido: análises literárias. Campinas: Papirus, 1988. 
RAMALHO, Fábio. A proliferação de dissidências: desordem cotidiana e trabalho no cinema latino-americano contemporâneo. Dissertação (Mestrado). Programa de Pós-Graduação em Comunicação, Universidade Federal de Pernambuco, 2009.

RANCIÈRE, Jacques. A democracia literária: entrevista concedida a Leneide Duarte-Plon, publicada em 18/12/2007. Disponível em:

http://p.php.uol.com.br/tropico/html/textos/2943,1.shl Acesso em 22 jun. 2018.

. A partilha do sensível: estética e política. 2 ed. Tradução: Mônica Costa Netto. São Paulo: EXO experimental org.; Editora 34, 2009.

SACHERI, Eduardo. O segredo de seus olhos. Tradução de La pregunta de sus ojos: Joana Angélica d'Ávila Melo. Rio de Janeiro: Objetiva, 2011.

SANTOS, Luís Fernando Amâncio. Ação, logo, cinema: o engajamento político do movimento de Cinema Novo a partir de sua produção escrita e do filme "Garrincha, alegria do povo" (1963). Dissertação (Mestrado). Programa de Pós-Graduação em História da Faculdade de Filosofia e Ciências Humanas, Universidade Federal de Minas Gerais, 2012.

SENDRÓS, Daniel. El secreto de sus ojos (los de Juan José Campanella). In: Revista Criterio. Buenos Aires, $\mathrm{n}^{\mathrm{o}}$ 2352, set. 2009. Disponível em:

$<$ http://www.revistacriterio.com.ar/cultura/el-secreto-de-sus-ojos-los-de-juan-josecampanella/>. Acesso em 22 jun. 2018.

SILVA, Denise Tavares. As viagens de Salles, Solanas e Sarquís: identidade em travessias. Tese (Doutorado) - Programa de Pós-Graduação em Integração da América Latina, Universidade de São Paulo, 2009.

STAM, Robert. O espetáculo interrompido: literatura e cinema de desmistificação. Tradução: José Eduardo Moretzsohn. Rio de Janeiro: Paz e Terra, 1981.

THEIDON, Kimberly. Entre prójimos: el conflicto armado interno y la política de la reconciliación en el Perú. Lima: IEP (Instituto de Estudios Peruanos), 2004.

WAUGH, Patricia. Metafiction: the theory and practice of self-conscious fiction. Routledge: London and New York, 1984.

WHISKY. Direção: Juan Pablo Rebella, Pablo Stoll. Produção: Fernando Epstein, Christoph Friedel, Hernán Musaluppi. Intérpretes: Andrés Pazos, Mirella Pascual, Jorge Bolani. Roteiro: Gonzalo Delgado, Juan Pablo Rebella, Pablo Stoll. Uruguai-Argentina-AlemanhaEspanha: Control Zeta Filmes, 2003. 1 DVD (95 min), son., color.

WISNIK, José Miguel. O som e o sentido. São Paulo: Companhia das Letras, 1989. 